Research Article

\title{
The Thermal Performance of Chinese Vernacular Skywell Dwellings
}

\author{
Gang Yao, ${ }^{1}$ Dongting Han, ${ }^{1}$ Li Zhang, ${ }^{2}$ and Zhongcheng Duan ${ }^{1}{ }^{1}$ \\ ${ }^{1}$ School of Architecture and Design, China University of Mining and Technology, Xuzhou 221116, China \\ ${ }^{2}$ Department of Architecture and Built Environment, The University of Nottingham, Nottingham NG7 2RD, UK
}

Correspondence should be addressed to Zhongcheng Duan; duanzhongcheng@126.com

Received 27 November 2020; Accepted 30 May 2021; Published 21 June 2021

Academic Editor: Xun Xi

Copyright (c) 2021 Gang Yao et al. This is an open access article distributed under the Creative Commons Attribution License, which permits unrestricted use, distribution, and reproduction in any medium, provided the original work is properly cited.

The aim of this research was to investigate the thermal performance of Chinese vernacular skywell dwellings. This was done by the analysis of on-site measurements of the environmental performance and computer simulation of solar conditions of eight vernacular skywell dwellings in three villages in southeastern China-Xidi, Zhifeng, and Yuyuan. Through the discussion of several heat inputs and outputs, it can be concluded that evaporative cooling had a substantial influence on the temperature in the skywells of dwellings in Xidi and Zhifeng villages. In addition to the buffering of temperature by thermal mass, evaporative cooling was found to further reduce the fluctuation in temperature inside the skywell and is likely to have been the main reason that the mean dry bulb temperatures inside the skywells in these villages were lower than the mean external dry bulb temperatures. Moreover, the construction materials of Chinese vernacular dwellings (skywell wall, floor material, wooden column, and panels) are likely to be hygroscopic.

\section{Introduction}

The forms of Chinese folk dwellings vary throughout China due to differences in geographical features and climate, local materials, defensive requirements, economic conditions, and the influence of religious factors. Chinese people have lived in houses of these designs for hundreds of years. They are all low-energy buildings created without external services at the time of construction. The courtyard house is the most numerous and most widely distributed type of traditional Chinese dwellings. Because of regional differences in landforms and climate, local materials, traditional building techniques and methods of construction, defensive requirements, religious traditions, and disparities in economic conditions, courtyard houses take different forms in different parts of China. In southeastern China, due to the dense population, the historically great economic prosperity, the particular security requirements of certain villages, and the hot and humid climate, multistorey houses with high gables and a relatively small and compact courtyard evolved from the design of the basic courtyard house [1]. This type of open space is termed the skywell.

The existing published research on Chinese vernacular dwellings is largely concerned with the architectural culture, layout, form, and structure of buildings, building materials and decoration, and the architectural setting and historical circumstances within which dwellings were constructed. For different types of Chinese traditional dwellings, many scholars have also done a lot of research on their thermal environment. Yaodong dwellings in western China have a comfortable indoor thermal environment because Yaodong thick walls can effectively damp external temperature waves and keep steady inner surface temperature [2-5]. Traditional Tibetan houses use heavy walls with good thermal insulation and heat storage performance to improve the indoor thermal environment [6-8]. Gou et al. [9] believed the traditional dwellings are well adapted to the local climate during summertime through climate responsive analysis of ancient dwellings located in the village of Xinye. Huang et al. [10-14] considered the indoor thermal comfort of traditional 
vernacular dwellings in Huizhou to be well during summer due to good natural ventilation and sun shading, but not fully satisfactory during winter due to the poor air tightness. Zhu et al. [15-17] considered cliff-side caves can significantly improve the indoor thermal environment in winter by researching the thermal performance of cave dwellings in the cold area of China. Xu et al. [18] found that the traditional Earth dwelling is well adapted to the local climate during summer by researching two typical dwellings in Qinba mountainous areas constructed respectively with brick and Earth materials. Yang [19] examined the indoor thermal environment of two Earth constructions in Turpan Basin and found the indoor thermal environment is better than the existing brick buildings.

In recent years, some researchers have studied the improvement of traditional residential materials. Shi [20] found the material properties of foam concrete are suitable for thermally upgrading the hollow wall system in the Hui style vernacular dwellings. Nie et al. [21] examined the potential of improving indoor thermal comfort in the Tibetan area, and results indicated that an appropriate heat source from local bioenergy could achieve indoor thermal comfort. Gao [22] optimized the envelope materials of $\mathrm{Gu}$ Yao in northern Shaanxi, and the materials can reduce the thickness of the enclosure structure and enhanced its characteristics of warm winter and cool summer. Wang and Zhang [23] considered that expanding the south of the sun room in the Tibetan area to ensure that as much as possible solar thermal radiation on the building so as to improve the indoor temperature. $\mathrm{Xi}$ et al. [24] found the interface transition zone between aggregates and mortar significantly affects the cracking behaviour of concrete, which is linked to the indoor thermal environment. However, there is little published information on the quantitative thermal performance of Chinese vernacular dwellings with skywells. Through the analysis of on-site measurements and computer simulation of the environmental performance of eight vernacular skywell dwellings in three villages in southeastern China-Xidi, Zhifeng, and Yuyuan, the influencing factors of the thermal environment in these dwellings are investigated.

\section{Area Description and Methodology}

2.1. Research Area Description. The three villages-Xidi (118E, 29.91 N), Zhifeng (117.67 E, 29.28 N), and Yuyuan (119.66 E, $28.77 \mathrm{~N}$ ) are in the eastern part of China with similar latitude and longitude (Figure 1). They are all in hilly areas. Each of the three villages developed around at least one stream because of the need for easy access to water for drinking and washing. With the advent of tap water in the 1990s, building a house near a natural source of water is not necessary any more.

The skywell plays important symbolic and ergonomic roles in Chinese vernacular dwellings. The skywell is designed to collect water and catch the wind [25]. Water in Chinese culture represents wealth. Therefore rainwater falling on the roof has to be collected and diverted into the house to avoid the loss of the "wealth." A skywell house is usually symmetrical and rectangular in plan (Figure 2). The core of the layout is a skywell, with rooms around the skywell on three or four sides. The skywell and an open hall facing into the skywell lie on the long axis of the ground plan. The dwellings are generally two or three storeys high because the population of the village was relatively large in relation to its available land. The dense arrangement of most of the houses in the three villages studied provides effective mutual shading in summer.

Three main types of skywell dwelling can be found in these villages: the three-in-one skywell house, the four-inone skywell house, and the H-shaped skywell house (Figure 2). The three-in-one type can be considered as a prototype, while in the four-in-one skywell house, two three-inone houses are joined together face-to-face, with a common skywell. In the H-shaped skywell house, two three-in-one houses are joined together back to back. They have individual skywells on opposite sides of the two-house block. Three-in-one skywell houses are mostly found in Xidi village and Yuyuan village, while $\mathrm{H}$-shaped skywell houses are mainly in Zhifeng village. In summary, the dwellings in Yuyuan village enclose a large central area, and the skywells of these houses can be regarded as courtyards. Skywells in Xidi village are not as large as those in Yuyuan village and skywells in Zhifeng village are quite small.

In order to assess thermal performance within the dwellings and to evaluate the relationship between building design and performance, air temperature, relative humidity, surface temperatures, and wind velocity within and outside the house were obtained. A total of 8 houses (Table 1)Yingfu dwelling, Dunren dwelling and Lufu dwelling in Xidi village; Panmaotai dwelling and Panxianxiong dwelling in Zhifeng village; Yufengfa dwelling, Gaozuo dwelling, and Shuting dwelling in Yuyuan village-were investigated in detail. These dwellings were chosen because they are representative of the traditional dwellings in their villages and because permission to study them was successfully obtained from the house owners.

The principal materials used in creating a Chinese vernacular dwelling are as follows:

(1) Wood (Chinese fir), used to make wall panels, columns, and the overhanging frames supporting eaves tiles.

(2) Brick, in two $2 \mathrm{~cm}$ layers enclosing a wide void $(26 \mathrm{~cm})$ filled with mud and sand stones of various sizes to form the external walls.

(3) White lime, used to paint the walls (with many patches of grey discolouration and green algae growth).

(4) Stone, used to pave the area at the foot of the skywell where the water trough is located

(5) A blend of finely divided materials used to create the floor around the edges of the skywell floor under the roof overhang. Different mixtures were used; mixtures might include sand, while lime, small stones, tung oil, or rice slurry.

(6) Fired clay, used to make the roof tiles of the overhang eaves. 


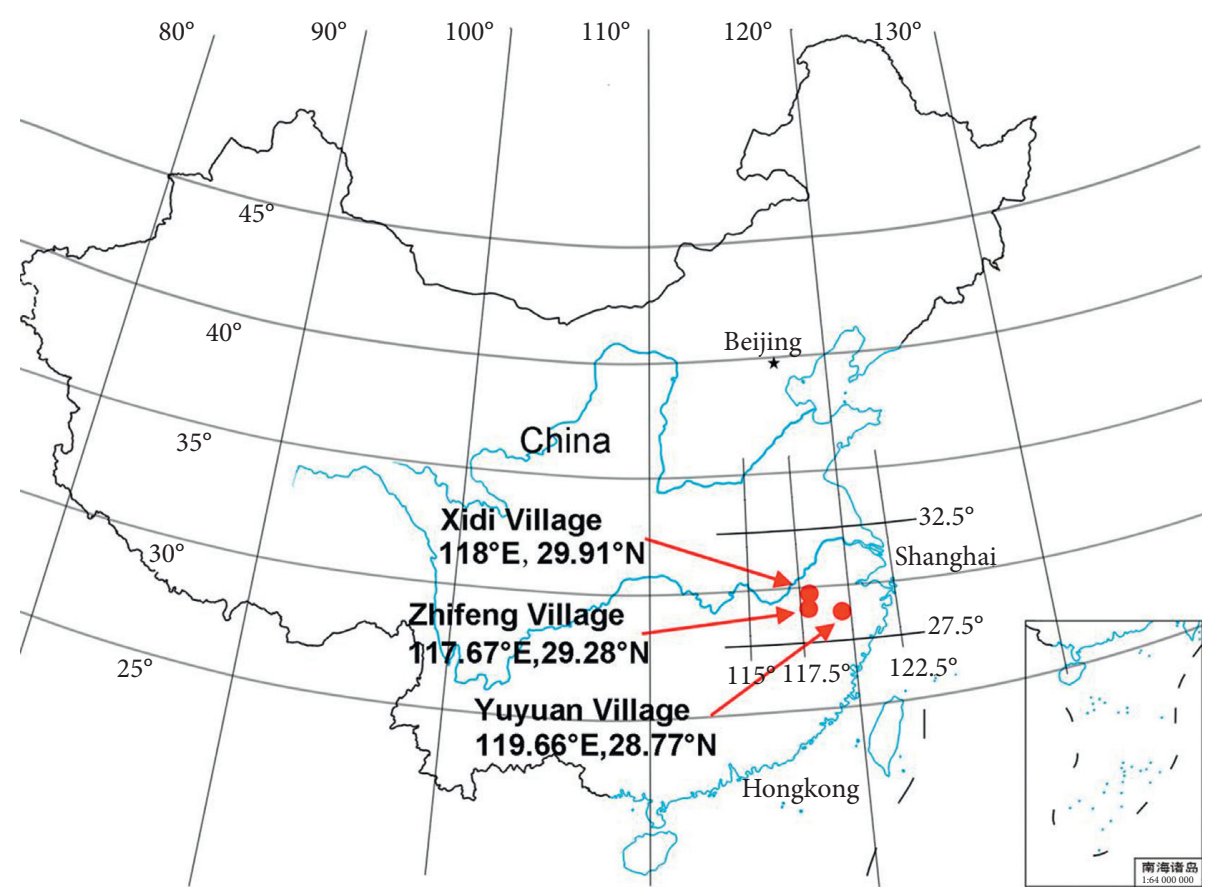

FIgURE 1: Location of three villages in China.
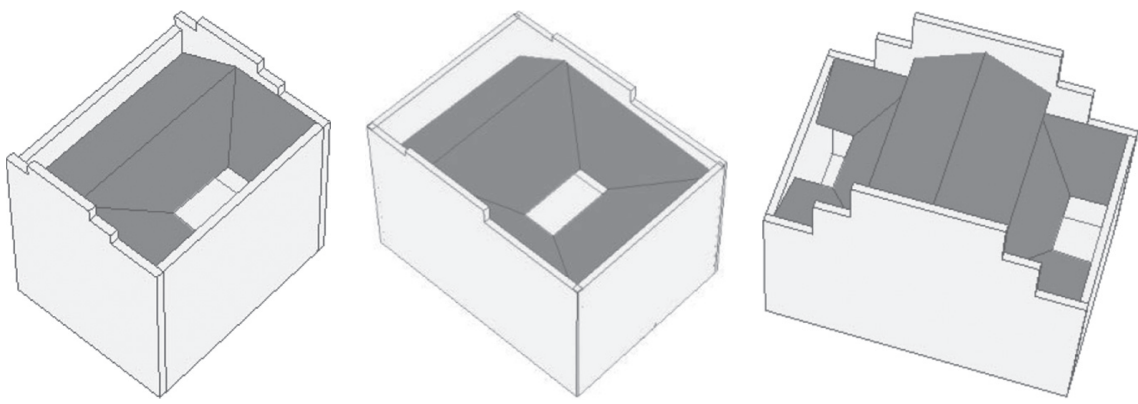

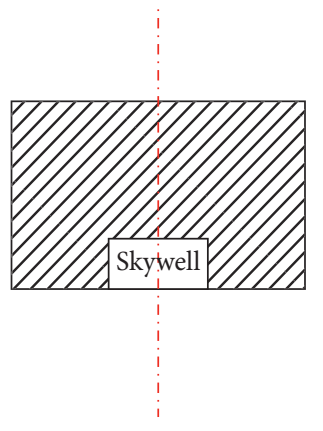

Three-in-one

(a)

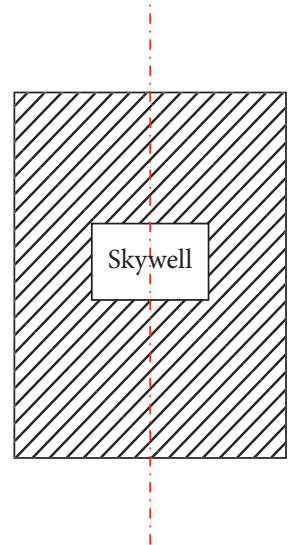

Four-in-one

(b)

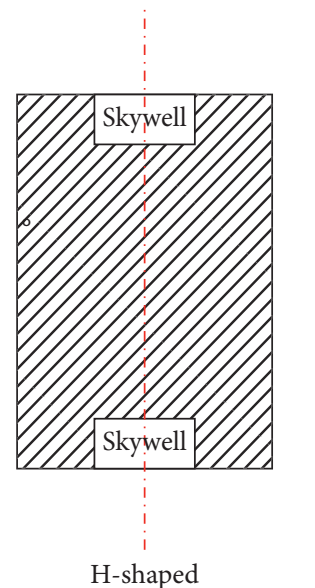

(c)

FIgURE 2: Main dwelling types in three villages studied. 
TABLE 1: Basic information of the dwellings.

\begin{tabular}{lcc}
\hline No. & Dwellings' name & Villages' name \\
\hline 1 & Lufu skywell & \\
2 & Yingfu skywell & Xidi village \\
3 & Dunren skywell & \\
\hline 4 & Gaozuo skywell & \\
5 & Shuting skywell & Yuyuan village \\
6 & Yufengfa skywell & \\
\hline 7 & Panmaotai skywell & Zhifeng village \\
8 & Panxianxiong skywell & \\
\hline
\end{tabular}

\subsection{Measurement and Simulation}

2.2.1. Air Temperature and Relative Humidity. Air temperature and humidity within the dwellings were recorded using data loggers (Gemini Data Loggers, UK). Data loggers who had been set to record the dry bulb air temperature (DBT) and relative humidity $(\mathrm{RH})$ every minute were placed in the skywell, the hall, and a bedroom of each house. Data loggers were placed at an approximate height of $1.5 \mathrm{~m}$. For comparison, in each village, the DBT of air outside the dwellings was measured by placing a data logger on a flat roof of a contemporary building near the studied vernacular dwellings to record the microclimate of the village. Data collected by this reference data logger was then compared with that collected within the dwellings. Data loggers located in skywells and rooftops were protected from sunlight and rain, while those placed inside the buildings were placed on items of furniture.

DBT and RH were recorded continuously over seven days in summer in the eight houses studied in detail. Equivalent data were collected for the eight houses in the three villages in winter, but only data for the houses in Xidi and Yuyuan are presented; data for the houses in Zhifeng were obtained later in February than data from the other two villages and were distinctly higher. As a result, winter data from Zhifeng were judged not to be comparable to winter data from Xidi and Yuyuan. In this study, external air temperature or external DBT indicates the temperature recorded on the roof, which is the external temperature used for compassion against internal temperature.

The position of the data logger (DL) within a specimen studied dwelling (the Dunren dwelling) is shown in Figure 3.

2.2.2. Direct Solar Radiation into the Skywell Void. The amount of solar radiation which penetrates into the skywells of the eight studied dwellings was calculated using Ecotect software. The parameters used were weather data from EnergyPlus, building dimensions, and default values for the properties of construction materials within Ecotect. In this simulation, data from the summer period $\left(1^{\text {st }} \mathrm{Jun}-31^{\text {st }}\right.$ Aug $)$ were used. The use of computer simulation allows longer periods to be considered than would have been possible with on-site measurement.

\section{Results and Analysis}

In each village, the DBT and $\mathrm{RH}$ data inside and outside the skywells of vernacular dwellings studied are shown in
Figures 4-8. During the summer measuring period, the ambient air of the three villages was hot and humid. The minimum external DBTs were all over $21^{\circ} \mathrm{C}$, and the maximum and mean external DBTs was $39.5^{\circ} \mathrm{C}$ and $27.6^{\circ} \mathrm{C}$ in Xidi, $41.6^{\circ} \mathrm{C}$ and $29.6^{\circ} \mathrm{C}$ in Zhifeng, and $39.2^{\circ} \mathrm{C}$ and $27.6^{\circ} \mathrm{C}$ in Yuyuan. Most of the time, the RH was over $60 \%$ in the three villages. In the winter testing period, the ambient air of Xidi and Yuyuan village was very cold but not very humid. The minimal and mean external DBTs were $-7.0^{\circ} \mathrm{C}$ and $1.7^{\circ} \mathrm{C}$ in Xidi and $-6.7^{\circ} \mathrm{C}$ and $3.5^{\circ} \mathrm{C}$ in Yuyuan.

For each village, on each of the study days, maximal external DBT was observed around 14:00 and minimal external DBT around 05:00 in summer and 08:00 in winter in the early morning before the sun rose. The external DBT and RH fluctuated considerably; the mean external diurnal swings in Xidi, Zhifeng, and Yuyuan villages in summer were calculated to be $12.5^{\circ} \mathrm{C}, 15.4^{\circ} \mathrm{C}$, and $11.8^{\circ} \mathrm{C}$. In the winter testing period, the mean diurnal swings were $11.8^{\circ} \mathrm{C}$ in Xidi and $18.7^{\circ} \mathrm{C}$ in Yuyuan.

The fluctuations of DBT and RH inside the skywells of vernacular dwellings were much smaller than the fluctuations of these values measured in the external air. The diurnal swing inside the skywells was found to be much lower than that of ambient air, especially in Xidi and Zhifeng villages-the mean diurnal swing inside the skywell dwellings of Xidi village, Zhifeng village, and Yuyuan village were $2.8^{\circ} \mathrm{C}$ in summer and $3.2^{\circ} \mathrm{C}$ in winter; $2.0^{\circ} \mathrm{C}$ in summer; $4.7^{\circ} \mathrm{C}$ in summer and $7.6^{\circ} \mathrm{C}$ in winter, respectively. Thus, the occupants of these skywell dwellings experience a relatively stable thermal environment. In the summer measuring period, considering data from all the studied houses in each village, the monitored DBTs inside the skywells ranged from $20.8^{\circ} \mathrm{C}$ to $29.0^{\circ} \mathrm{C}$ in Xidi, from $21.9^{\circ} \mathrm{C}$ to $27.9^{\circ} \mathrm{C}$ in Zhifeng, and from $22.6^{\circ} \mathrm{C}$ to $32.5^{\circ} \mathrm{C}$ in Yuyuan. It was found to be much cooler inside the skywell than in the external air, which is probably why the residents of the houses in the three villages were satisfied with the thermal condition of their houses in summer. In the winter testing period, although the fluctuation of DBTs was much smaller inside the skywell than that of outside, the DBTs were too low to be comfortable, and the residents of all three villages studied reported low satisfaction with the thermal condition of the houses. The RH values inside the skywells of these studied dwellings in summer were very high-always over $85 \%$ in Zhifeng, 75\% in Xidi, and 70\% in Yuyuan - which could lead to thermal discomfort in still air condition.

In the summer measuring period, the mean DBTs inside the skywells of the Dunren, Yingfu, and Lufu dwellings of Xidi village were $25.0^{\circ} \mathrm{C}, 24.6^{\circ} \mathrm{C}$, and $24.7^{\circ} \mathrm{C}$, respectively, which were, respectively, $2.6^{\circ} \mathrm{C}, 3^{\circ} \mathrm{C}$, and $2.9^{\circ} \mathrm{C}$ less than the mean external DBT $\left(27.6^{\circ} \mathrm{C}\right)$. The mean DBTs inside the east side skywell of Panmaotai dwelling and the south side skywells of Panxianxiong dwelling of Zhifeng village were $25.3^{\circ} \mathrm{C}$ and $25.6^{\circ} \mathrm{C}$, respectively, which was $4.3^{\circ} \mathrm{C}$ and $4.0^{\circ} \mathrm{C}$ less than the mean external DBT $\left(29.6^{\circ} \mathrm{C}\right)$. In Yuyuan village, the mean DBTs inside the skywells of the Yufengfa, Shuting, and Gaozuo dwellings were $26.9^{\circ} \mathrm{C}, 27.3^{\circ} \mathrm{C}$, and $27.1^{\circ} \mathrm{C}$, respectively; these values were close to the mean external DBT $\left(27.6^{\circ} \mathrm{C}\right)$. 


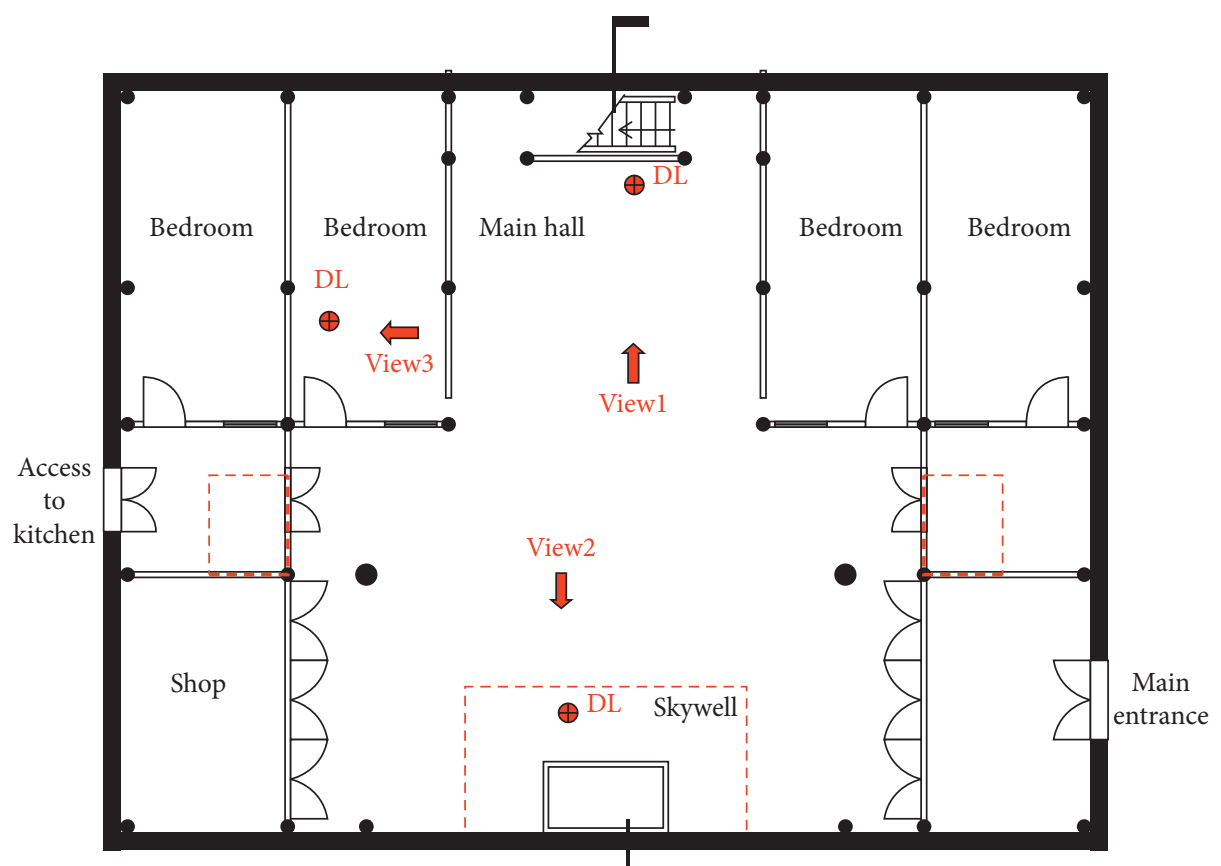

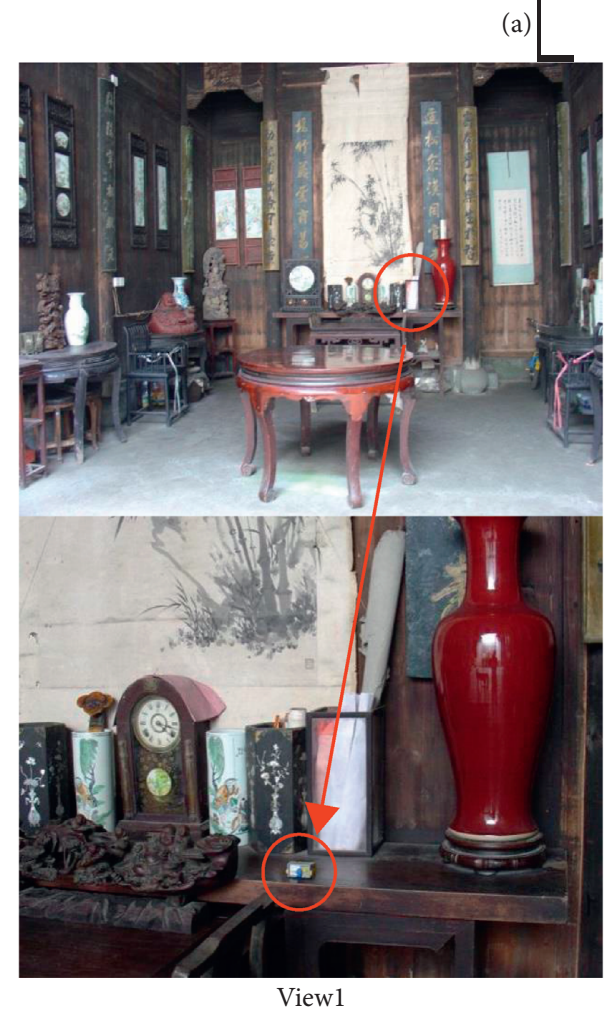

(b)

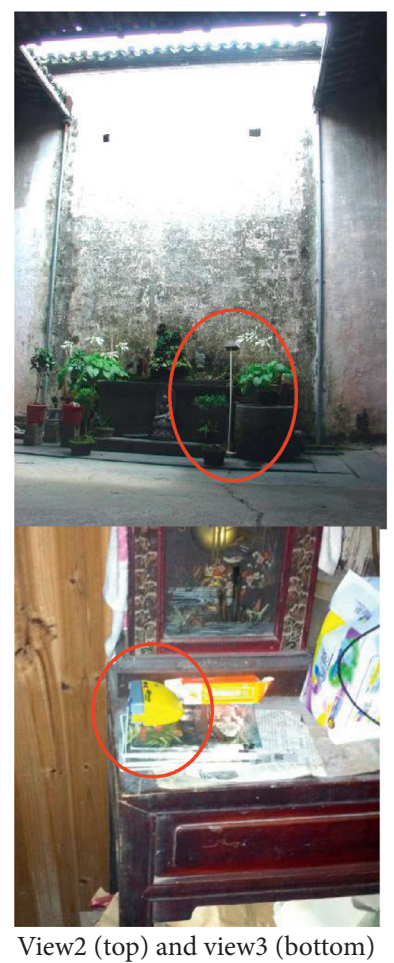

(c)

Figure 3: Positions of data loggers in Dunren dwelling.

On each of the summer recording days, the peaks in the DBT traces obtained in the skywells of the eight dwellings studied were distinctly smaller than the external DBTs, while the trough values were close to the external DBTs. On each of the winter recording days, both the peaks and troughs were considerably smaller than the external DBTs.
For all of the houses, on each of the recording days, there was found to be a time lag between the attainment of maximal external DBT and attainment of maximal DBT in the skywells and between the attainment of minimal external DBT and attainment of minimal DBTs in the skywells. However, the time lag observed in skywell dwellings varied 


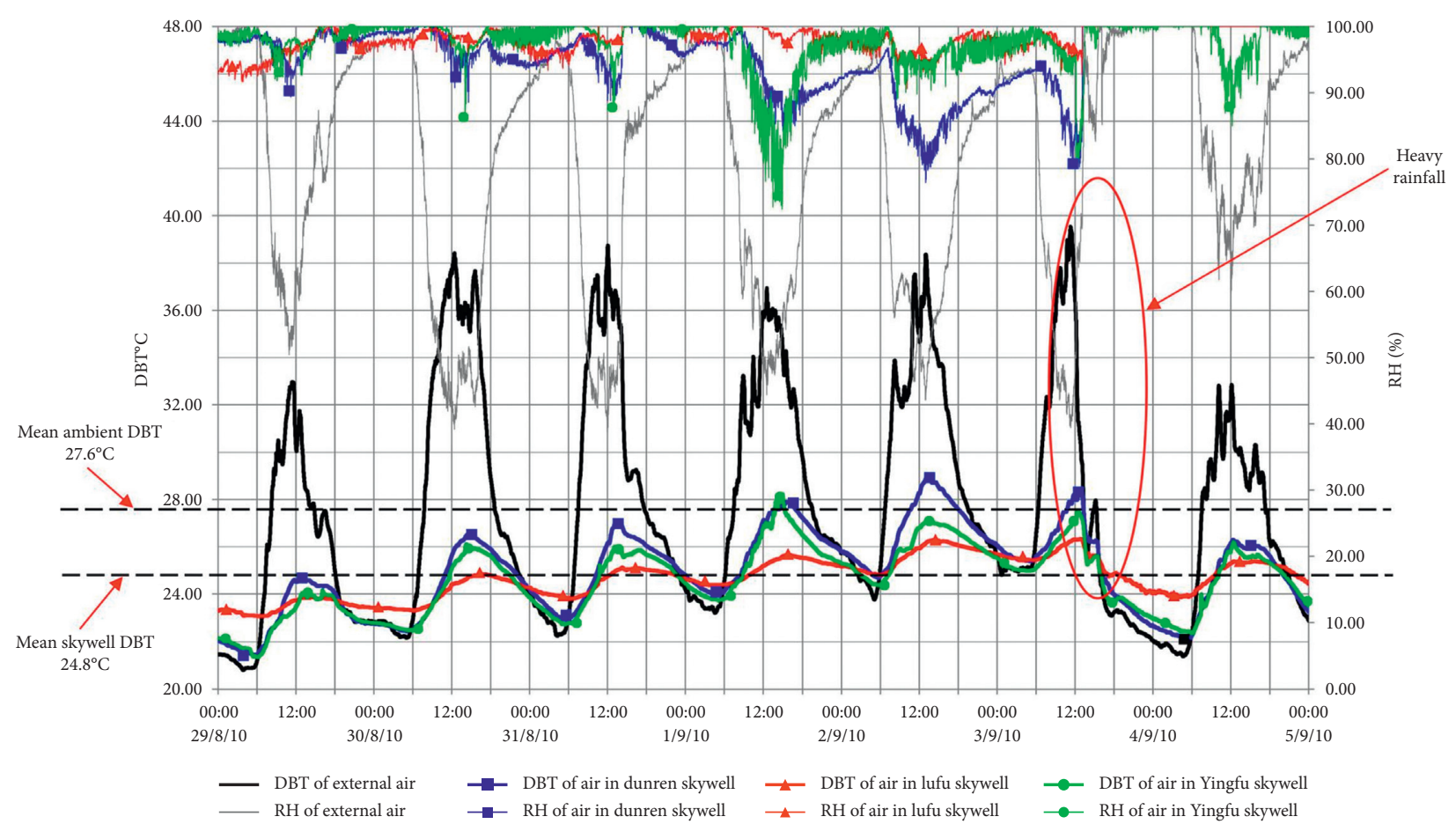

Figure 4: Temperature and relative humidity data for dwellings in Xidi village in summer recording period.

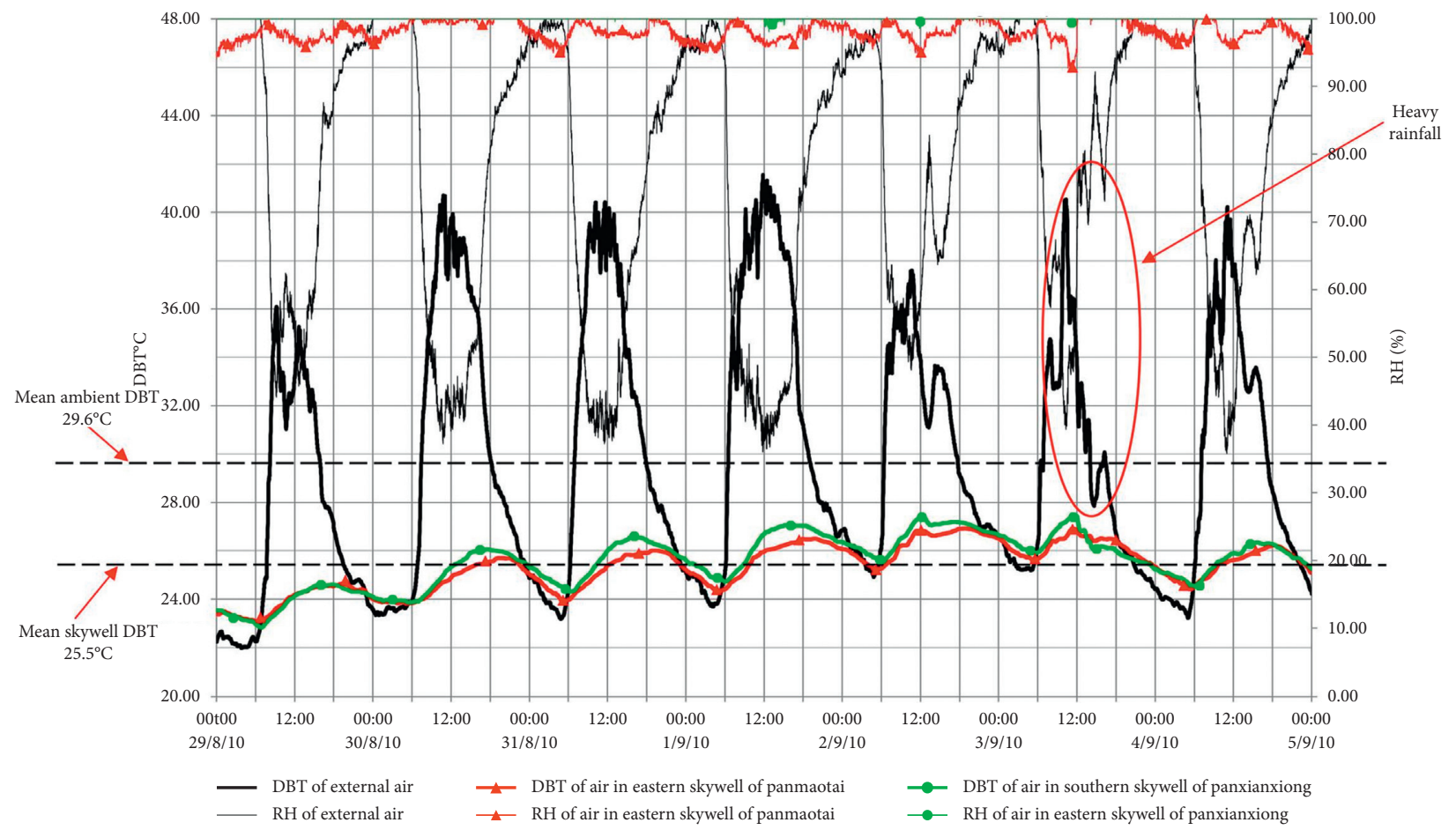

Figure 5: Temperature and relative humidity data for dwellings in Zhifeng village in summer recording period.

from day to day. While the material properties of each dwelling remain constant, wind speed and direction vary considerably from day to day, leading to variation in the lag time between the attainment of maximal external and skywell DBTs. In each of the houses, the mean time lag between the attainment of maximal external temperature and maximal temperature in the bedrooms was much longer than the corresponding time lag between the attainment of maximal external temperature and maximal temperature in the skywells. For example, in Xidi village, the mean time lag 


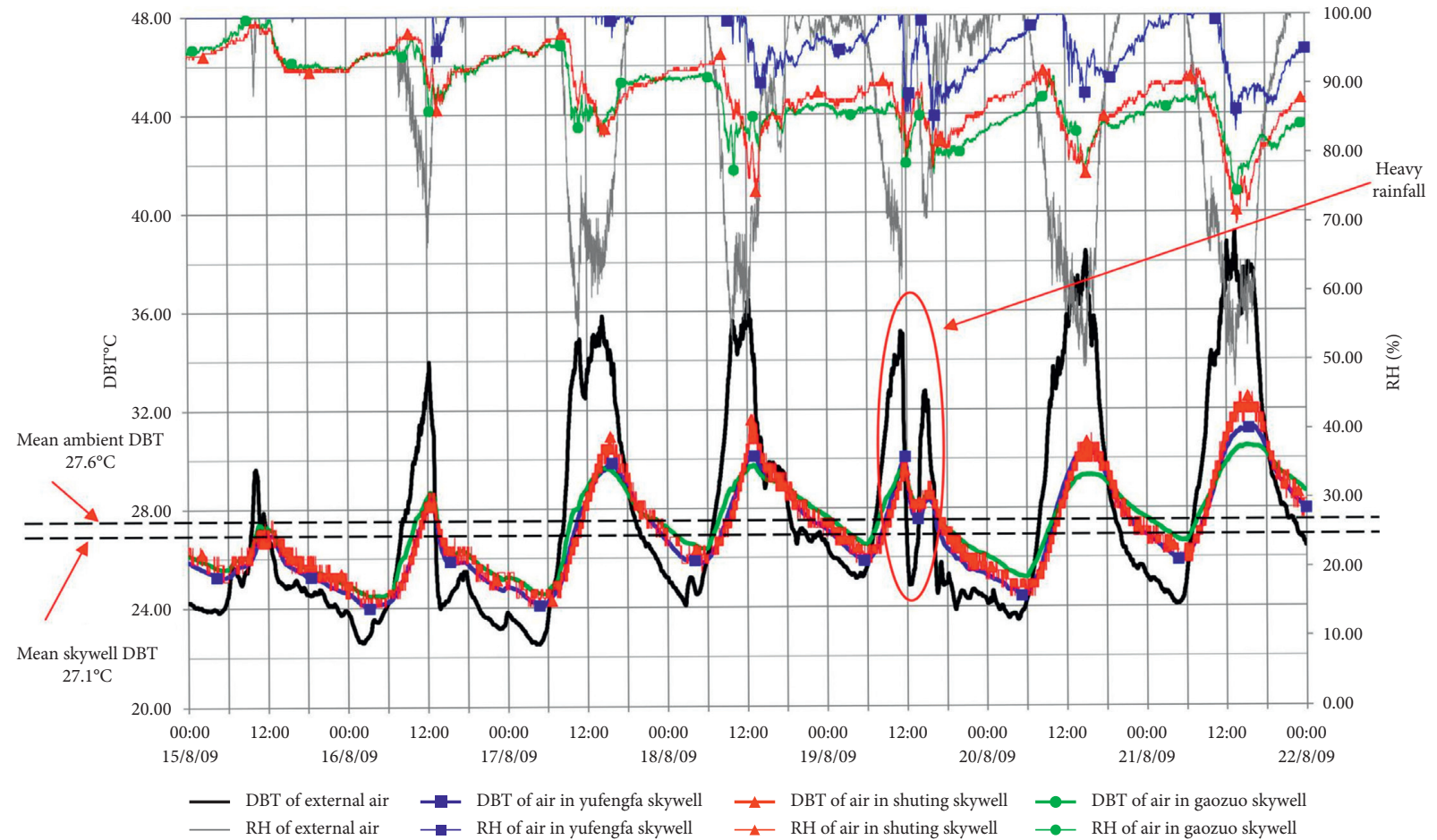

FIGURE 6: Temperature and relative humidity data for dwellings in Yuyuan village in summer recording period.

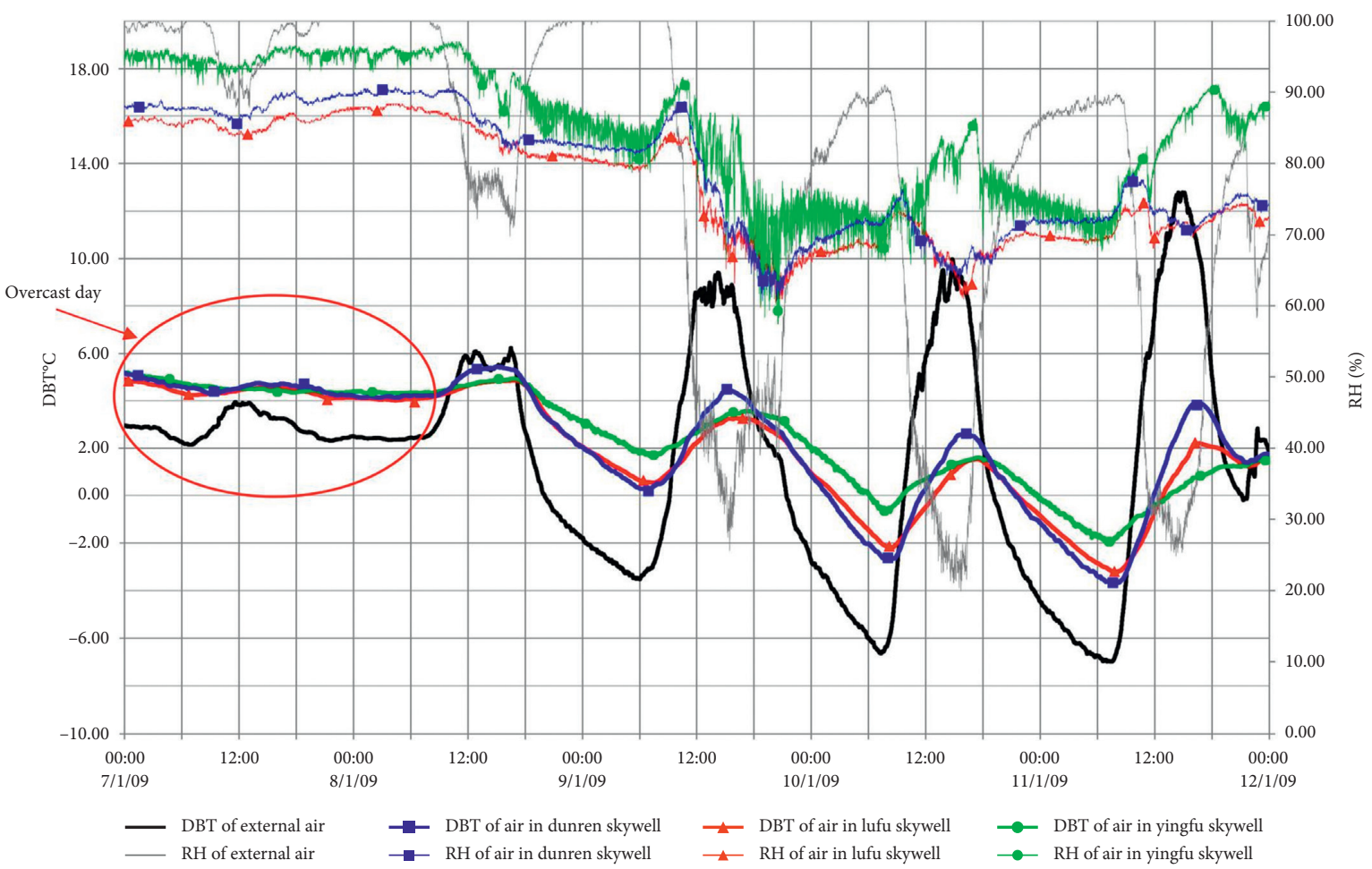

Figure 7: Temperature and relative humidity data for dwellings in Xidi village in winter recording period.

in skywells was about 1.5 hours, while in bedrooms, the mean time lag was about 4 hours.

At any sky condition, the ambient $\mathrm{RH}$ reverses with the DBT-when DBT increases, the RH decreases; when the DBT reaches its peak, the $\mathrm{RH}$ reaches its trough, vice versa. The reason is as follows: the RH is the ratio of the actual amount of moisture in the air compared to the maximum amount that the same air can contain. When the absolute humidity 


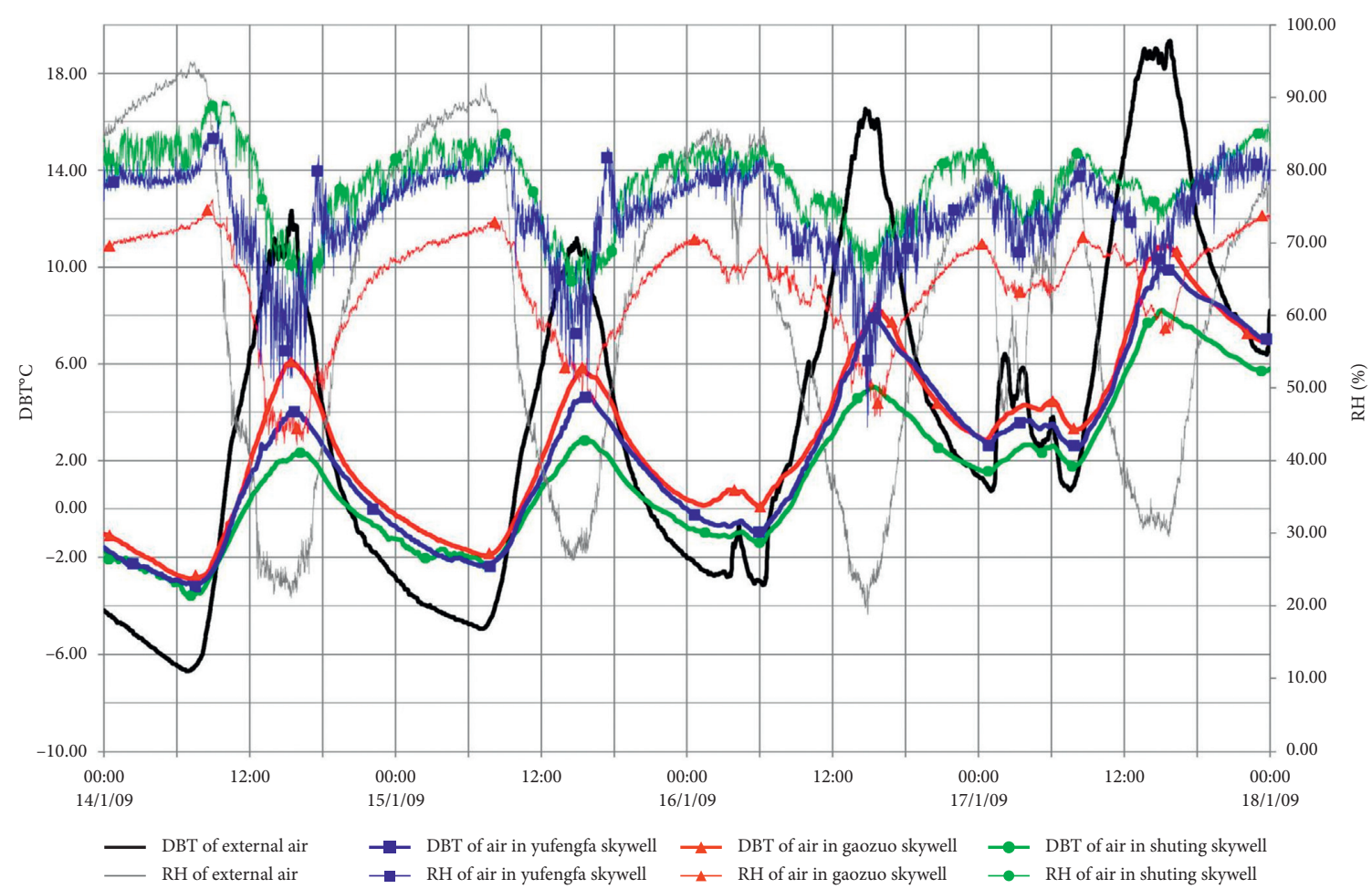

FIGURE 8: Temperature and relative humidity data for dwellings in Yuyuan village in winter recording period.

$(\mathrm{AH})$ is constant, with higher DBT, the maximum amount of moisture that can be held is increased; thus, the $\mathrm{RH}$ decreases.

In summary, from the thermal recording data, it can be concluded that the design of Chinese vernacular skywell dwellings is mainly intended to counteract excessive summer heat than uncomfortable winter cold (although the presence of only a very small number of openings in the walls of the buildings might in part be a measure to combat extreme winter temperatures by reducing heat loss). Therefore the manner in which the house designs achieve lower subexternal DBTs inside the skywells and general improvement in summer thermal comfort was investigated in depth. The exploration of this topic is described in Section 4. The following points are considered:

(1) Why was the fluctuation of DBTs inside the skywell reduced considerably in relation to the external air?

(2) Why was the mean DBT inside the skywell found to be $2.6^{\circ} \mathrm{C}-4.3^{\circ} \mathrm{C}$ lower than the mean external DBT in Xidi and Zhifeng villages but very close to the mean external DBT in Yuyuan village?

\section{Discussion}

This section analyzes the thermal environment of the skywell as a thermal system. The thermal environment of the skywell is discussed in detail with respect to three main types of heat inputs and outputs-evaporative heat loss, incident solar radiative heat gain, and conductive heat gain/loss.
4.1. Effect of Evaporation. During the summer testing period, evidence of evaporation was found in skywell dwellings of Xidi and Zhifeng villages but not in Yuyuan village. Evaporation can reduce the air temperature inside the skywell markedly, given the high latent heat of vaporisation of water. With $1 \mathrm{~g}$ water evaporated, the amount of energy used is about $2400 \mathrm{~J}$. This amount of energy could reduce $1 \mathrm{~kg}$ of air by $2.4^{\circ} \mathrm{C}$. The absolute humidity $(\mathrm{AH})$ inside and outside the skywells of the studied dwellings was calculated through the use of CYTPsyChart software (CYTSoft Technology, USA) based on the DBT and RH data obtained by site monitoring.

4.1.1. Results. During the summer measuring period, the $\mathrm{AH}$ in the ambient air in the three villages was very high-more than $16 \mathrm{~g} / \mathrm{kg}$ in Zhifeng, $15 \mathrm{~g} / \mathrm{kg}$ in Xidi, and $17 \mathrm{~g} / \mathrm{kg}$ in Yuyuan. The time course of $\mathrm{AH}$ inside and outside the skywells was similar to that of DBT-peak values of AH were observed around noon time and the trough values were observed before the sun rose, since evaporation increases with temperature, raising the $\mathrm{AH}$ of the air (Figures 9-11).

In Yuyuan village, the $\mathrm{AH}$ inside the skywell dwellings was very close to the ambient $\mathrm{AH}$, while in Xidi and Zhifeng villages, there was a considerable difference between the $\mathrm{AH}$ inside and outside the skywells. The $\mathrm{AH}$ inside the skywells was generally higher than the ambient $\mathrm{AH}$, and the greatest difference was found around 12:00 every day. It follows from this that the greatest degree of evaporative cooling would have taken place when the outside ambient air was hottest (see temperature data in Figures 4-5). 


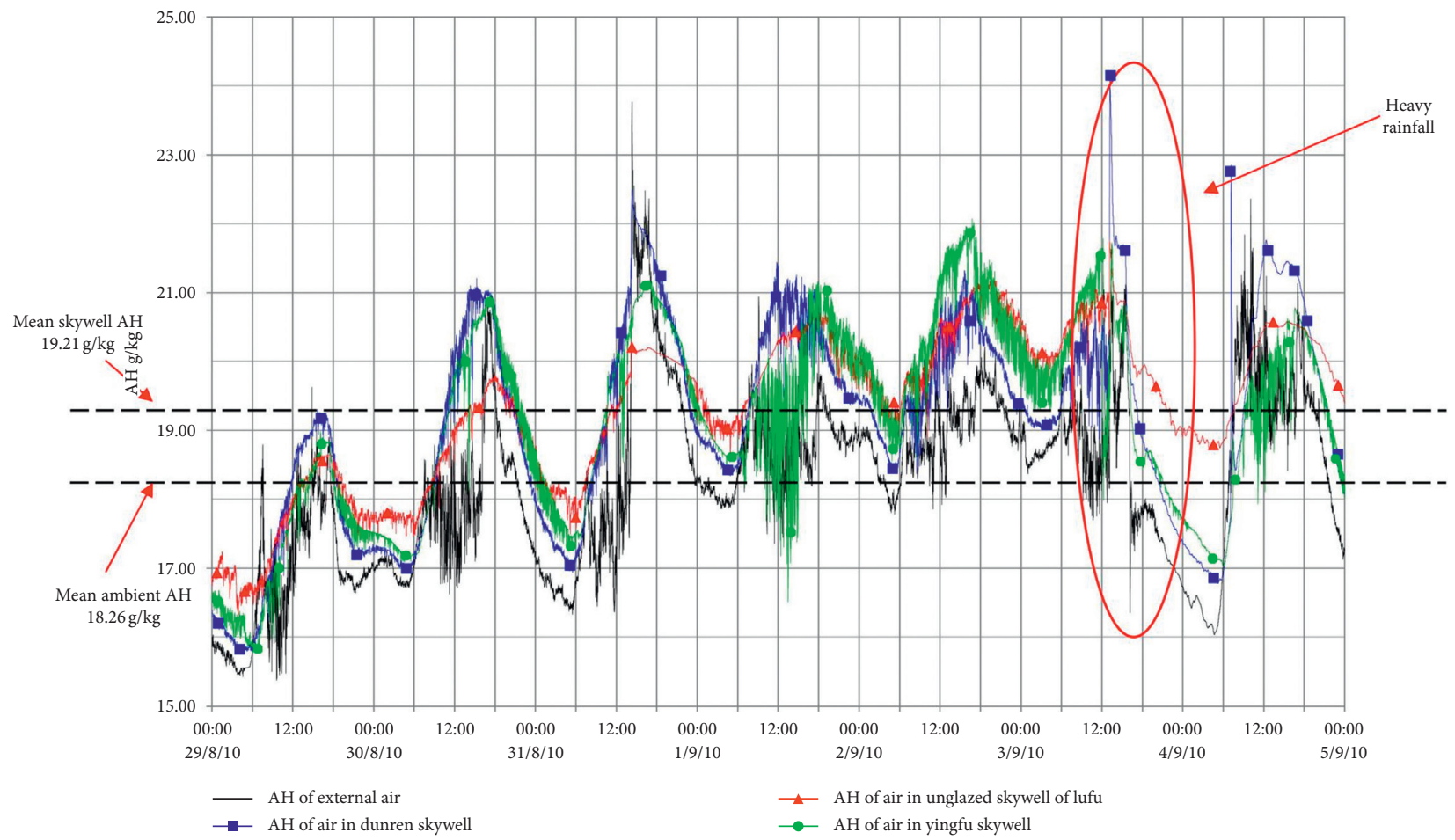

Figure 9: Absolute humidity data for dwellings in Xidi village in summer recording period.

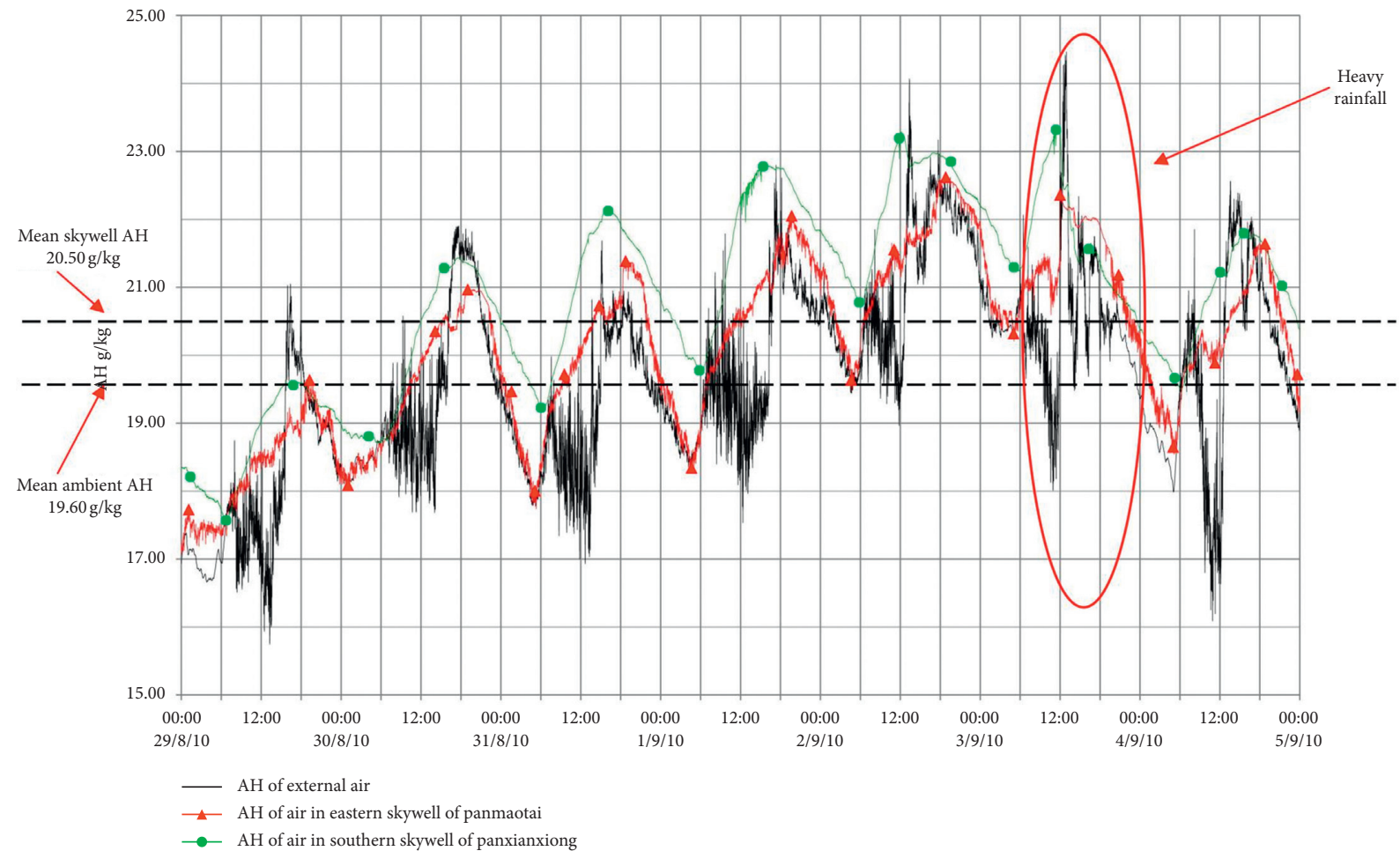

FIGURE 10: Absolute humidity data for dwellings in Zhifeng village in summer recording period.

It can be seen in Figures 9-10 that the AH of the air inside the skywell is usually higher than that of the external air throughout the diurnal cycle. It can therefore be concluded that evaporation did occur in skywells of dwellings of
Xidi and Zhifeng villages. The AH inside the skywells of dwellings of Xidi village was much higher than the ambient $\mathrm{AH}$ even at night; in Zhifeng village, the $\mathrm{AH}$ inside the southern skywell of Panxianxiong dwelling was markedly 


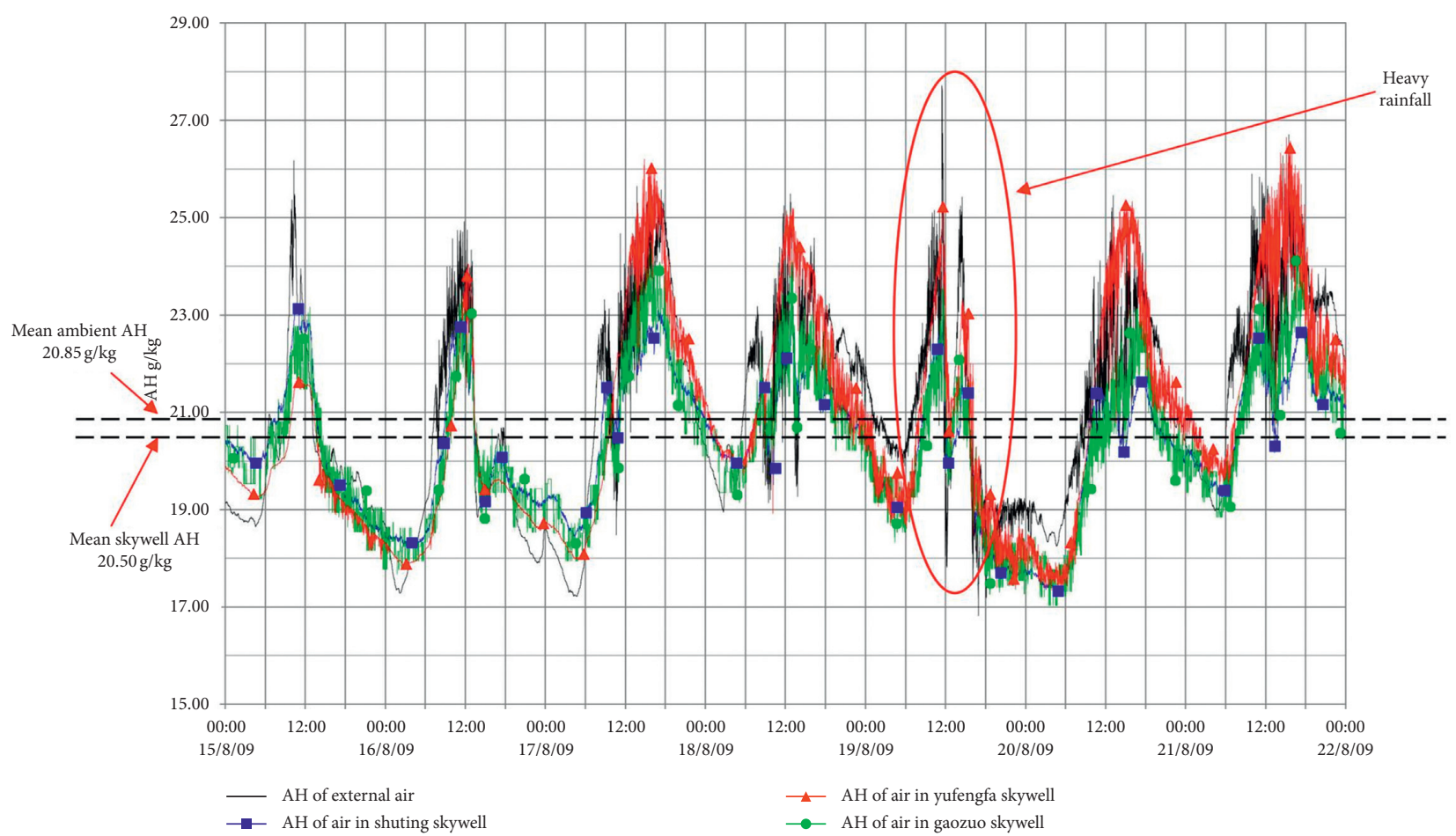

Figure 11: Absolute humidity data for dwellings in Yuyuan village in summer recording period.

higher than the ambient $\mathrm{AH}$, and the $\mathrm{AH}$ in the skywells of the Panmaotai dwelling. These observations will be explained below. In winter, little difference was found between the $\mathrm{AH}$ inside the skywells of the studied dwellings and the external $\mathrm{AH}$ at any time (data not shown). It follows that little evaporation occurred within the skywells in winter.

4.1.2. Discussion. Sources of water for evaporation within the skywell are water held within construction materials (all houses), water in the traditional stone trough (present in most skywell houses), and water from the skywell floor (regularly deposited in some skywell houses). These are discussed below.

(1) Stone Trough. In traditional Chinese skywell dwellings, rainwater is collected in a stone trough at the foot of the skywell.

(2) Water Contained in Construction Materials. The construction materials of vernacular dwellings investigated in the present study are hygroscopic, which can accumulate rainwater (when exposed to the external environment) and atmospheric water vapour (from the internal and external environment). A piece of grey brick wall material and a piece of floor material (both obtained as loose fragments) (Figure 12) were dried in a microwave oven, weighed, immersed in water for 24 hours, and reweighed. The grey brick was found to absorb $19.1 \%$ of its dry weight during the immersion period and the floor material $14.2 \%$. Unpainted and untreated cedar, the most commonly used wood in the fabrication of the panels and columns of the houses investigated in the present study, has been shown to be able to absorb more than $100 \%$ of its mass in water. Water can be absorbed and released by these hygroscopic materials according to the temperature and humidity of the air.

(3) Water from Skywell Floor. The residents of skywell dwellings sometimes pour water on the skywell floor in summer. In the Yingfu dwelling in Xidi village, occupants always wash their clothes in the skywell and pour the washing water on the ground floor (Figure 13). Occupants of the Panxianxiong dwelling in Zhifeng village pour waste water into a form of small trough consisting of a number of eight thin flat pieces of stone arranged vertically (Figure 14). Within the boundary of the trough, there is a hole in the floor. Waste water from the trough drains through the hole and into the underlying void.

In some houses investigated in the present study, there was found to be more than one source of water for evaporation in the skywell. These cases are discussed below.

(4) Water for Evaporation Principally from Wet Skywell Surfaces and Secondarily from Water Trough. The principal water sources for evaporation within the skwyells appear to be the water trough, the damp/wet inner surface of the skywell wall, and (in some skywells) the wet floor. It is likely that the wet surfaces make a larger contribution to evaporation since the area of the wet surfaces is much larger than the surface area of the water trough.

For example, during the recording period in the Yingfu dwelling (Xidi village), evaporation was found to occur at a rate sufficient to influence temperature in the skywell (see Figure 9) despite the water container being very small and in spite of there being no skywell wall which could store water. 


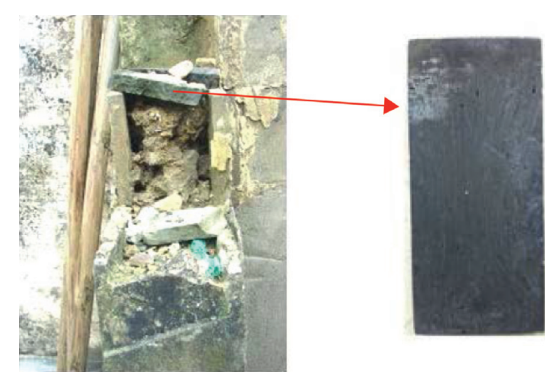

(a)

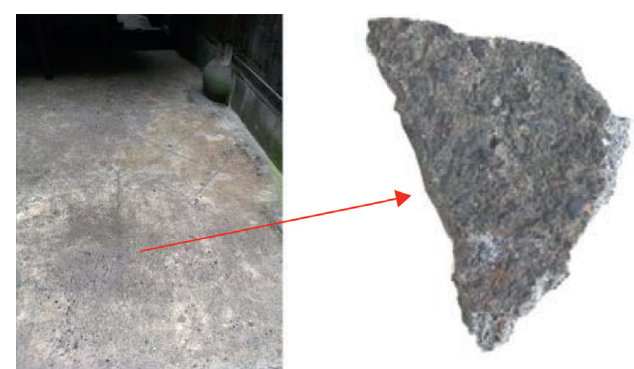

(b)

Figure 12: Samples of wall and floor material in Chinese vernacular dwellings.

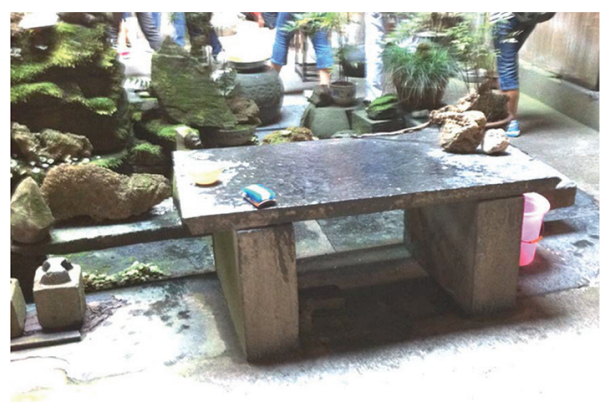

FIgURe 13: Additional water sources from washing clothes in skywell of Yingfu dwelling (Xidi village).

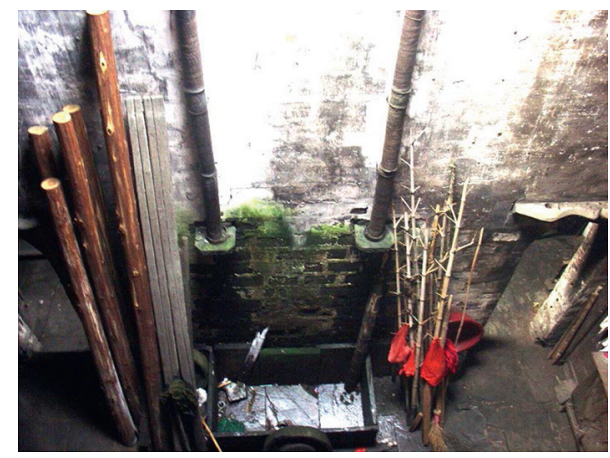

FIGURE 14: Waste water poured into trough made of flat pieces of stone by residents of Panxianxiong dwelling (Zhifeng village).

This is because there is a large wet area on the skywell floor. In the skywell of the Yingfu dwelling, an area of the floor is given over to a traditional combined arrangement of potted plants interspersed with ornamental rocks. The plants do not appear to be intentionally watered; instead, they acquire water in the form of spray from waste water as residents discharge it into the skywell, and from rain. The rocks and the surfaces of the plants and pots add substantially to the surface area of the floor; they thus add to the capacity of surfaces within the skywell to retain water. In addition, the decorative rocks are covered in moss and algae, which can retain a considerable quantity of water per unit area of their growth. Thus, the surfaces within the skywell of the Yingfu dwelling can hold a great reserve of water for evaporation, which is able to increase the $\mathrm{AH}$ of the air within the skywell above the ambient value.
In Zhifeng village, the $\mathrm{AH}$ inside the southern skywell of the Panxianxiong dwelling was markedly higher than the ambient $\mathrm{AH}$ and higher than the $\mathrm{AH}$ in the eastern skywell of the Panmaotai dwelling (see Figure 10). This is despite there being no water contained in the water trough (see Figure 14). In the eastern skywell of the Panmaotai dwelling, the sources of water for evaporation are round ceramic water but of traditional design and the inner surface of the skywell wall, which can acquire and retain rainwater. The southern skywell of the Panxianxiong dwelling can also acquire and retain rainwater at the inner surface of the skywell wall. In addition, the occupants of this building always pour their waste water into a small, rudimentary trough close to one edge of the skywell floor. Because of initial splashing as the water is thrown into the trough and the perviousness of the gaps between the stone sheets, the troughs do not retain water; water that does not drain down the hole in the floor at the base of the trough wets the nearby walls and floor. The area of the visibly wet wall and floor surface greatly exceeds the corresponding area observed in the eastern skywell of the Panmaotai dwelling.

4.2. Effect of Incident Solar Radiation. The solar gain within the skywell depends on the solar irradiance, the size of the skywell, and the transmittance of the skywell glazing, if present. When the skywell is small, the amount of solar radiation penetrating into a skywell dwelling is restricted. The amount of solar radiation which penetrates into the skywells of the eight studied dwellings was estimated using Ecotect software (Figure 15). The results are shown in Table 2. 


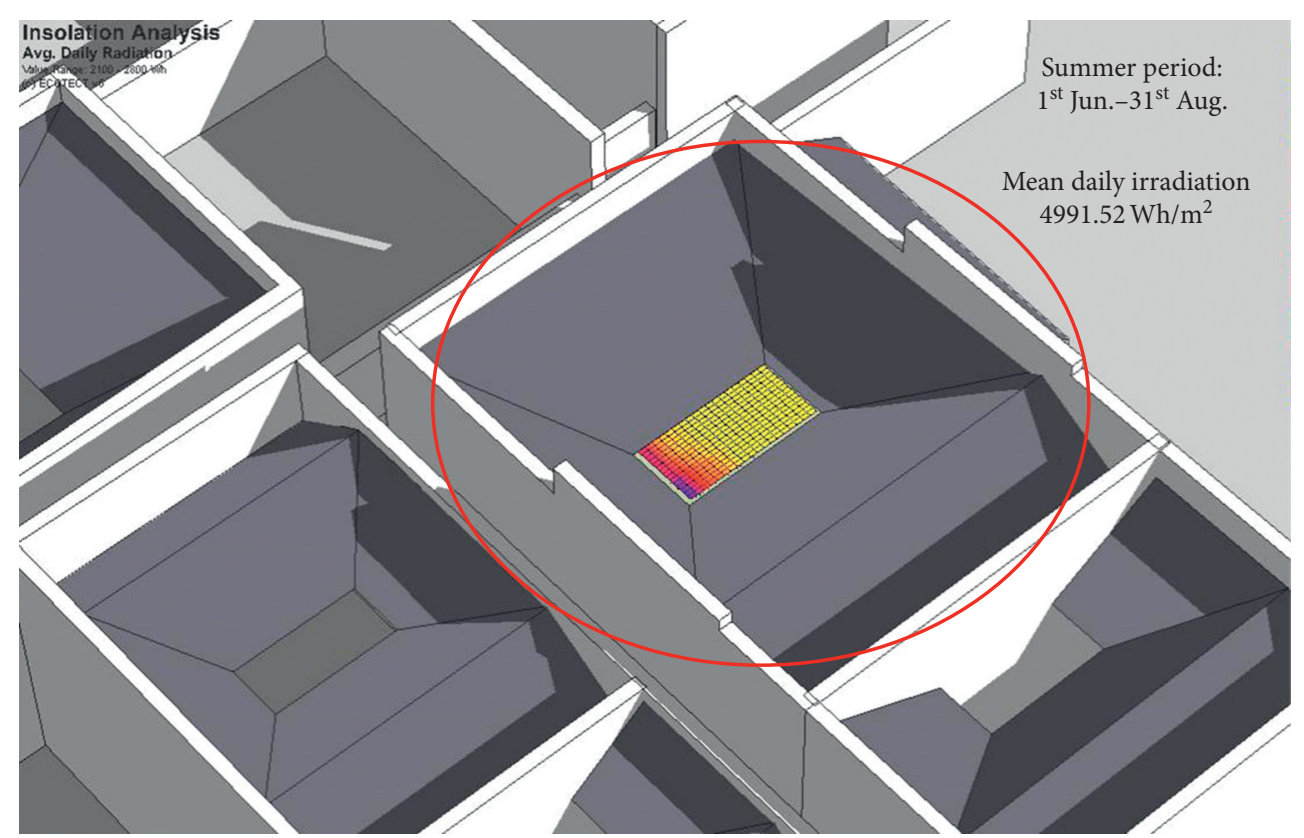

FIGURE 15: Average daily irradiation incident on Yingfu skywell in the summer period.

In Table 2, it can be seen that dwellings in Xidi and Zhifeng villages receive much less incident solar radiation through skywells than dwellings in Yuyuan village due to the small size of the skywells in Xidi and Zhifeng. When the sun is shining, the temperature of the air within a skywell is raised by incident solar radiation. Part of this radiation is also absorbed by the construction materials of the skywell; these materials absorb short-wave solar radiation and release long-wave radiation, which can be absorbed by the air within the skywell. Some heat is lost to the exterior by reflection.

In site measurements, the air in the skywells of the dwellings in Yuyuan village was hotter with larger diurnal swing than those in Xidi and Zhifeng even though the ambient air in Yuyuan was slightly cooler than that in Xidi and Zhifeng. The dwellings in Yuyuan village receive a large amount of solar radiation through their large skywells, and the thermal environment within them is more influenced by solar radiation than the air in the skywells in Zhifeng and Xidi (see Figures 4-6).

The amount of solar radiation penetrating into a skywell dwelling is restricted when the skywell is narrow. The tall white horse-head wall and mutual shading of vernacular dwellings can reduce indirect solar gain considerably.

4.3. Effect of Conduction. In the hot summer daytime, conductive heat gain within the skywell arises from the high external surface temperature of the house and the high external air temperature.

The design of Chinese vernacular dwellings minimizes indirect solar gain by the shading effect of white horse-head walls and the surrounding dwellings. The construction materials of vernacular dwellings have low thermal conductance and high thermal mass, which together reduce the peak thermal load and the total heat gain by storing a lot of heat and delay the entry of the heat into the interior (see Section 4.3.1).

\subsubsection{Thermal Conductance of Walls of Chinese Vernacular} Dwellings. The exterior walls of Chinese vernacular dwellings are generally thick ( $300 \mathrm{~mm}$ approx.) - two $2 \mathrm{~cm}$ layers of brick enclose a wide void $(26 \mathrm{~cm})$ filled with mud and sand stones of various sizes (Figure 16). The thermal properties of these materials are listed in Table 3.

The bedrooms in the dwelling do not directly abut the exterior wall; there is a $50 \mathrm{~mm}$ air gap between the wall and the wooden panels lining the room. The air gap provides further insulation, reducing heat gain in summer and heat losses in winter. The thermal conductivities of air and timber are also listed in Table 3. Using measurements of the thickness of the components of the wall of the Lufu dwelling in Xidi village and the data in Table 3, the thermal conductance of the walls was calculated to be $1.8 \mathrm{~W} / \mathrm{m}^{2} \mathrm{~K}$ excluding the contribution of the inner boarding and the air space, and $0.36 \mathrm{~W} / \mathrm{m}^{2} \mathrm{~K}$ with the inclusion of the inner boarding and the air gap in the calculations (a $2 \mathrm{~mm}$ thick layer of air was assumed to be present in the walls to allow for the air spaces in the sand stones layer). The $50 \mathrm{~mm}$ air gap between the wall and the wooden panel lining the room is the main contributor to the low thermal conductance $\left(0.36 \mathrm{~W} / \mathrm{m}^{2} \mathrm{~K}\right)$; however, the air gap is not sealed, so this low thermal conductance might not be achieved.

Diurnal fluctuation in the temperature of the air in the bedrooms of the eight dwellings studied lagged behind those observed in temperatures measured in the skywells. Fluctuations in bedroom air temperature were also smaller. The lower thermal conductance of bedrooms due to the air gap and the interior wooden panels contribute to the time lag. Another reason for the lag is that with direct openings (doors 
TABLE 2: Mean daily solar irradiation Q incident upon the skywells in the summer period (1st Jun-31st Aug) for the eight dwellings studied (where Q derived from proximal weather station data and ecotect software).

\begin{tabular}{lcccc}
\hline Village & $\begin{array}{c}\text { Dwelling names and designations of skyells } \\
\text { (in parentheses) }\end{array}$ & $\begin{array}{c}\text { Dimensions } \mathrm{L} \times \mathrm{W} \times \mathrm{H} \\
(\mathrm{m})\end{array}$ & WI & $\begin{array}{c}\text { Mean daily incident solar irradiation on the skywell } \\
(\mathrm{Q})\end{array}$ \\
\hline \multirow{2}{*}{ unit: kWh }
\end{tabular}

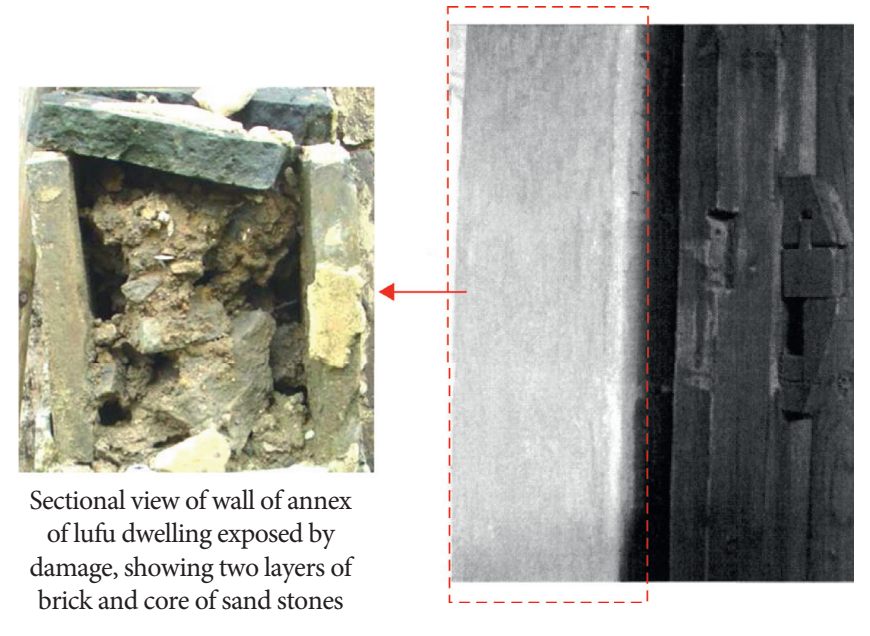

(a)

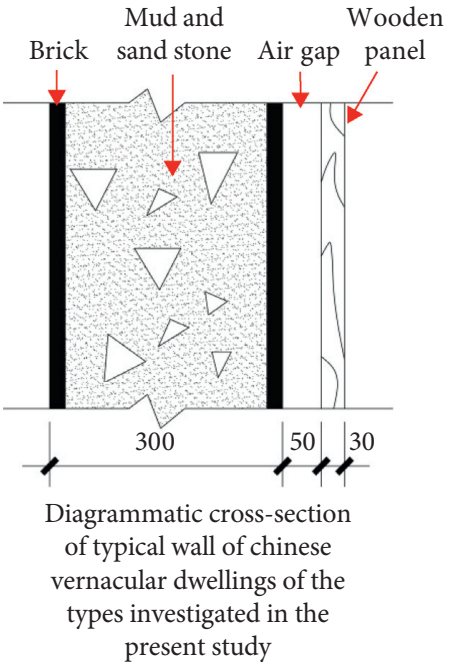

(b)

Figure 16: Composition of walls of Chinese vernacular dwellings.

and skywell) to the outside, the air exchange rate within the skywell is more frequent than the exchange rate within the bedroom since only a small opening facing the skywell is present in the bedroom if it is fully opened (Figure 17).

Furthermore, the annexes (such as the kitchen and the toilet) which adjoin the external walls act as buffers that provide further insulation for the whole dwelling.

4.3.2. Thermal Mass. Building materials of low thermal conductance retard heat transfer and cause a lag between fluctuations in external and internal temperatures. The amount of heat transferred and the rate of heat transfer are also influenced by the thermal mass of building materials.

In Table 3, it can be seen that the construction materials in vernacular dwellings have high density and specific heat. Szokolay [26] classifies buildings into either two or three categories according to specific mass (total mass divided by total floor area). A building can be considered as heavyweight if the specific mass $\left(\mathrm{kg} / \mathrm{m}^{2}\right)$ of the building (total mass of the building divided by the total floor area of the building) achieves the following criterion for two or three divisions in Table 4.

Using the density data given in Table 3 and measurements of the thickness of wall components, the specific mass of the type of wall encountered in the eight dwellings studied in detail and illustrated in Figure 16 was calculated to be over $400 \mathrm{~kg} / \mathrm{m}^{2}$ (e.g., $680 \mathrm{~kg} / \mathrm{m}^{2}$ in the Yingfu dwelling). The massive structure of Chinese vernacular dwellings acts as a heat sink. With their high heat capacity, the walls and floor absorb heat during the summer day and release it during the night. Thus, heat is stored in the construction materials and its entry into the dwelling is delayed. This leads to the reduction of the temperature fluctuation inside the skyell markedly. 
TABLe 3: Thermal properties and densities of materials in Chinese vernacular dwellings.

\begin{tabular}{lccc}
\hline & Thermal conductivity $(\mathrm{W} / \mathrm{mK})$ & Density $\left(\mathrm{kg} / \mathrm{m}^{3}\right)$ & Specific heat $(\mathrm{J} / \mathrm{kg} \mathrm{K})$ \\
\hline Brick & 0.62 & 1700 & 800 \\
Sandstone & 1.3 & 2000 & 800 \\
Mud & 1.25 & 1600 & 1000 \\
Timber & 0.115 & 544 & 1220 \\
Air & 0.025 & 1.15 & 1063 \\
\hline
\end{tabular}

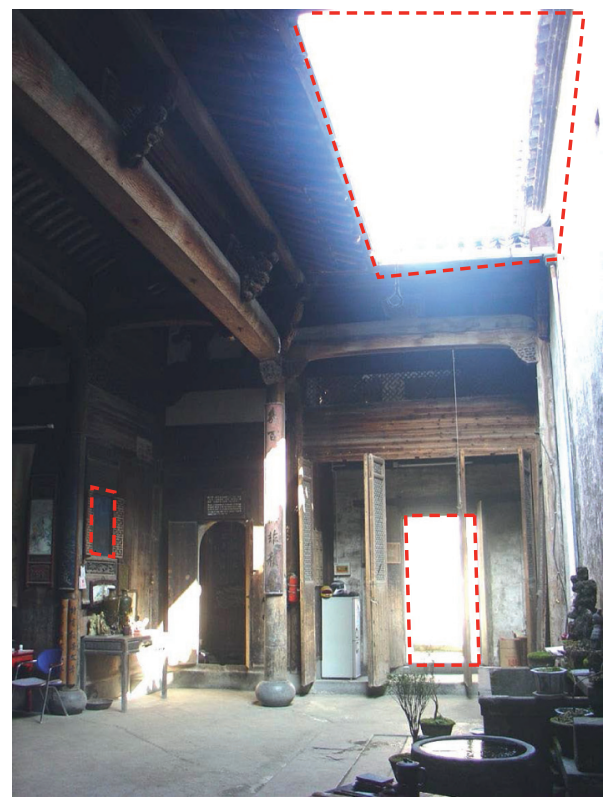

FIgURE 17: Large openings to the outside and small openings of bedroom to the skywell.

TABle 4: The criterion of the specific mass of the building.

\begin{tabular}{lc}
\hline Light & $<150 \mathrm{~kg} / \mathrm{m}^{2}$ \\
Medium & $150-400$ \\
Heavy & $>400$ \\
Light & $\leq 250 \mathrm{~kg} / \mathrm{m}^{2}$ \\
Heavy & $>250$ \\
\hline
\end{tabular}

\section{Conclusions}

According to the on-site measurement of vernacular skywell dwelling and the simulation of solar condition, as well as analysis of the results and discussion of several heat inputs and outputs, it can be concluded that

(1) Chinese vernacular dwellings were found to have high heat capacities (the specific mass of all the dwellings studied was calculated to be over $400 \mathrm{~kg} /$ $\mathrm{m}^{2}$ ). The massive structure of these dwellings is resistant to fluctuations in temperature.

(2) Evidence was obtained that evaporative cooling had a substantial influence on the temperature in the skywells of dwellings in Xidi and Zhifeng villages. This further reduced the temperature fluctuation inside the skywell and was likely to have been the main reason that the mean DBTs inside the skywells in these villages were $2.6-4.3^{\circ} \mathrm{C}$ lower than the mean external DBT. In the skywells of dwellings studied in Yuyuan village, the mean internal DBTs were very close to the mean external DBT; evidence was found that evaporation does not occur to an extent sufficient to influence skywell temperature in the courtyard-type skywells of Yuyuan.

(3) The construction materials of Chinese vernacular dwellings (skywell wall, floor material, wooden column, and panels) are likely to be hygroscopic.

(4) Dwellings in Zhifeng and Xidi villages receive much less incident solar radiation through skywells than dwellings in Yuyuan village, due to the small size of the skywells in Zhifeng and Xidi. The large skywell in Yuyuan village amass more solar radiation than those in Zhifeng and Xidi, leading to higher skywell temperatures and larger fluctuations in temperature in the Yuyuan dwellings.

\section{Data Availability}

The data used to support the findings of this study are included within the article.

\section{Conflicts of Interest}

The authors declare that they have no conflicts of interest. 


\section{Acknowledgments}

The authors would like to express my gratitude to those residents of vernacular dwellings who gave them permission to obtain measurements in their houses and who consented to be interviewed. This work received financial support from the CUMT Overseas Training Programme for Young Teachers (20190717).

\section{References}

[1] Z. C. Duan, The environmental performance of vernacular skywell dwellings in southeastern China, Ph.D thesis, The University of Nottingham, London, UK, 2012.

[2] J. Liu, L. Wang, Y. Yoshino, and Y. Liu, "The thermal mechanism of warm in winter and cool in summer in China traditional vernacular dwellings," Building and Environment, vol. 46, no. 8, pp. 1709-1715, 2011.

[3] X. Fan and B. Chen, "Theoretical analyses and predictions of indoor thermal environment for cave dwelling in northwest of China," Procedia Engineering, vol. 146, pp. 473-480, 2016.

[4] L. P. Tong and C. X. Xu, "Testing and evaluation of indoor and outdoor thermal environment of sunken cave dwelling in summer," Building Science, vol. 31, no. 2, pp. 9-14, 2015.

[5] X. P. Li and Y. Cui, "Field study on indoor thermal environment of sinking cave in Guanzhong area in winter," Journal of Xi'an University of Architecture and Technology (Natural Science Edition), vol. 51, no. 4, pp. 591-596, 2019.

[6] H. J. Sun and M. J. Leng, "Analysis of thermal environment in Tibetan traditional dwelling building in rural area of Gannan," Civil and Environmental Engineering, vol. 36, no. 5, pp. 29-36, 2014.

[7] Z. R. Li, "Indoor thermal environment of lhasa traditional residential solar house in summer," Building Energy Efficiency, vol. 47, no. 9, pp. 6-10, 2019.

[8] B. M. SuoLang and Q. Chang, "Study on climate adaptability of traditional residential buildings in Lhasa," Journal of Xi'an University of Architecture and Technology (Natural Science Edition), vol. 52, no. 3, pp. 416-423, 2020.

[9] S. Gou, Z. Li, Q. Zhao, V. M. Nik, and J.-L. Scartezzini, "Climate responsive strategies of traditional dwellings located in an ancient village in hot summer and cold winter region of China," Building and Environment, vol. 86, pp. 151-165, 2015.

[10] Z. J. Huang, M. Q. Yu, L. J. Zheng, C. Gong, and Z. Q. Wu, "One-year field study on indoor environment of Huizhou traditional vernacular dwellings in China," Procedia Engineering, vol. 205, pp. 1316-1322, 2017.

[11] Z. J. Huang, J. J. Liu, H. T. Hao, and Y. M. Dong, "Indoor humidity environment in Huizhou traditional vernacular dwellings of China in summer," Procedia Engineering, vol. 205, pp. 1350-1356, 2017.

[12] Z. J. Huang, "Analysis on field measurement of thermal environment of Huizhou traditional vernacular dwellings in summer," Building Science, vol. 33, no. 10, pp. 26-31, 2017.

[13] Z. J. Huang, M. Yu, L. Zheng, and C. Gong, "Indoor environment and comfort of Huizhou traditional dwellings," Civil and Environmental Engineering, vol. 40, no. 1, pp. 97-104, 2018.

[14] L. P. Zhu, "Thermal environment of 24 solar terms in Huizhou traditional residences," Building Science, vol. 36, no. 2, pp. 67-78, 2020.

[15] J. Zhu, C. Xing, and P. Nie, "Thermal performance of courtyard cave dwellings in western Henan province," Energy Procedia, vol. 158, pp. 559-564, 2019.
[16] J. Zhu, P. Nie, R. Li, and L. Tong, "Climate responsive characteristics of cliff-side cave dwellings in cold area of China,” Energy Procedia, vol. 158, pp. 2731-2736, 2019.

[17] X. Zhao, P. Nie, J. Zhu, and L. Tong, "Evaluation of thermal environments for cliff-side cave dwellings in cold region of China," Renewable Energy, vol. 158, pp. 154-166, 2020.

[18] J. Xu, Z. L. Lu, W. J. Gao, M. S. Yang, and M. L. Su, "The comparative study on the climate adaptability based on indoor physical environment of traditional dwelling in Qinba mountainous areas, China," Energy and Buildings, vol. 197, pp. 140-155, 2019.

[19] L. Yang, "Research on design strategy of green residential buildings in extreme dry hot dry cold climate," Industrial Construction, vol. 50, no. 7, pp. 28-33, 2020.

[20] X. Shi, "Thermal upgrading of Hui-style vernacular dwellings in China using foam concrete," Frontiers of Architectural Research, vol. 1, no. 1, pp. 23-33, 2012.

[21] Q. Nie, S. Zhao, Q. Zhang, and P. Liu, "An investigation on the climate-responsive design strategies of vernacular dwellings in Khams," Building and Environment, vol. 161, no. 2, Article ID 106248, 2019.

[22] B. Gao, "Analysis of green construction wisdom of guyao dwellings in Northern Shaanxi," Industrial Construction, vol. 50, no. 7, pp. 15-27, 2020.

[23] F. Wang and H. Y. Zhang, "Analysis and research on indoor thermal environment of sunshine house in Diqing Tibetan area in winter," Industrial Construction, vol. 50, no. 7, pp. 107-112, 2020.

[24] X. Xi, Z. Q. Yin, S. T. Yang, and C. Q. Li, "Using artificial neural network to predict the fracture properties of the interfacial transition zone of concrete at the meso-scale," Engineering Fracture Mechanics, vol. 242, no. 11, Article ID 107488, 2021.

[25] J. Duan, K. Gong, X. D. Chen, X. D. Zhang, and S. Peng, Kongjian Yanjiul: Shijie Wenhua Yichan Xidi Gucunluo Kongjian Jiexi. [Urban Space Research1: Space Analysis of World Cultural Heritage Site Xidi Ancient Village], University of Southeast, Nanjing, China, 2006.

[26] S. V. Szokolay, Introduction to Architectural Science-the Basis of Sustainable Design, Elsevier, Amsterdam, Netherland, 2008. 